\author{
Chemistry \\ Platform of the Swiss Academy of Sciences
}

\section{Translational Science: A Catalyst for Real World Applications?}

\section{Adrien K. Lawrence* \\ ${ }^{*}$ Correspondence: Dr. A. K. Lawrence, Swiss Academy of Sciences (SCNAT), Schwarztorstrasse 9, CH-3007 Bern, E-mail: chemistry@scnat.ch}

Science is the systemic search for new knowledge and innovative ideas. Scientific knowledge is empirically based and successful replication of the results is a crucial component of it. Translational science connects this knowledge with real world applications in order to address societal challenges and problems, under the condition that the science-policy interface is taken into account. The aim of this communication is to examine if translational science can be applied to research settings other than health care.

The concept of translational science (TS) or translational research was created in 1990s to describe the knowledge/ technology transfer occurring in pharmaceutical R\&D. ${ }^{[1-5]}$ The aims of translational science include fostering $R \& D$ by removing partition walls between specialists and by improving the bottlenecks and communication gaps that occur between each stage of R\&D in order to establish sustainable health policies for targeted populations in a more efficient way. Translational science is usually described in three phases as shown in Fig. 1. ${ }^{[2,3]}$

Research of new treatments is a long, highly complex, and uncertain process because of the scientific challenges associated with each step along the product lifecycle, from early research to treatment launch. Although the R\&D process appears to be well established, the meticulous planning and coordination required to support a successful technology transfer are often unrecognised. Each step in the product lifecycle involves a range of activities which are performed by specialists such as synthesis, clinical studies, or economic modelling. The findings from one step need to be communicated to the next group of specialists who may possess a different background. This knowledge transfer occurs at every stage of R\&D until product launch and establishment of new treatment/healthcare guidelines.

It is widely accepted that the elaboration of a new treatment takes between 10 and 20 years from inception to first product introduction and requires approximately 1 billion dollars with only 1 compound out of 5000-10'000 being successful..1] The emergence of new diseases such as neurodegenerative disorders, swine and avian flu, and the implementation of constraining health care policies in recent years have put more pressure on biopharmaceutical companies to come up with innovative solutions to health problems of increasing complexity while optimising R\&D. In a translational science setting, it is believed that delivering a compound in a time of seven years with a success rate closer to 1 in 250 is feasible. ${ }^{[1]}$

Furthermore, the need for improvement of new treatment and healthcare policies is reflected by the increasing number of dedicated translational science units or teams within pharmaceutical companies and in government agencies, and by the large increase of public funding including:

- The largest ever funding - up to $£ 775$ million over 5 years - to be made available for translational research in UK (7 March 2011)

- First two translational research partnerships launched in UK (6 October 2011)

- BMS partners with Duke Translational Medicine Institute (December 2011)

- Roche sets up academic translational centre in Zurich (7 December 2011)

- Partnership between Canadian Institutes of Health Research (CIHR) and the R\&D Health Research Foundation (HRF) to foster innovation in healthcare delivery (26 April 2012)

- NIH launches collaborative program with industry and researchers to spur therapeutic development (3 May 2012)

- The health research programme part of FP7 (€6'100 million) (2007-2013).

\section{Extending Translational Science to Other Fields}

Although translational science has mainly been used in healthcare and medicine, the methodology, the research setting, and the lessons learned should be considered by other fields given that the research community is facing challenges of increasing complexity. Energy, climate, materials, and development in general may benefit from applying a similar approach.

For example, the first photovoltaic cell was built by Becquerel in 1839 and the first practical one was elaborated by the Bell Laboratories in 1954.[6-8] Arrhenius predicted initially in 1896 an increase in the average Earth temperature of $4{ }^{\circ} \mathrm{C}$ to $6{ }^{\circ} \mathrm{C}$ if the concentration of $\mathrm{CO}_{2}$ doubled before revising it to $2.1^{\circ} \mathrm{C} .{ }^{[9]}$ In 2013, the IPCC estimated a likely temperature increase in the range of $1.5^{\circ} \mathrm{C}$ to $4.5^{\circ} \mathrm{C}$ if the same phenomenon occurred. ${ }^{[10]}$

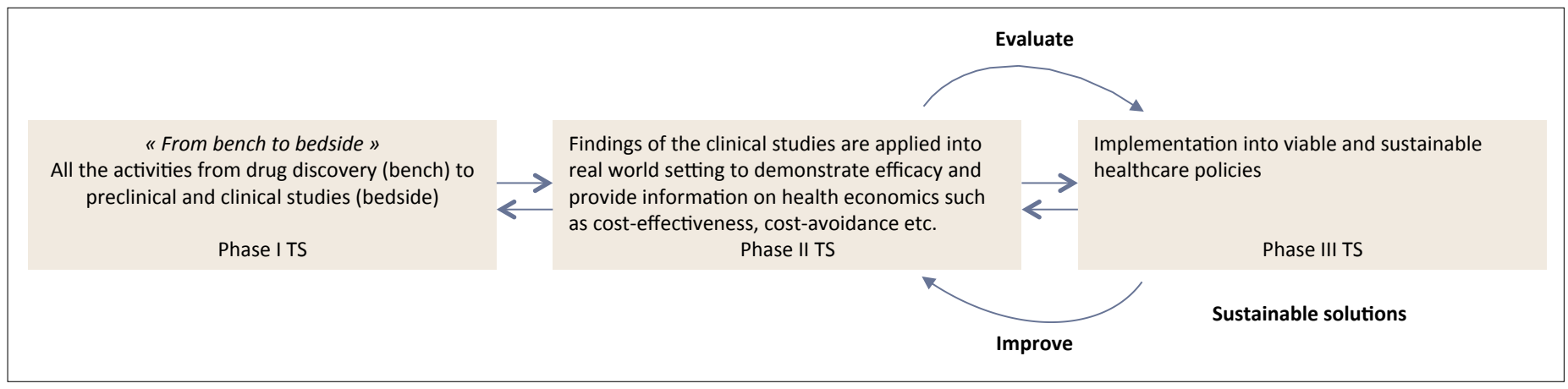

Fig. 1. The three phases involved in translational science (TS). Source: Adapted from ref. [2]. 


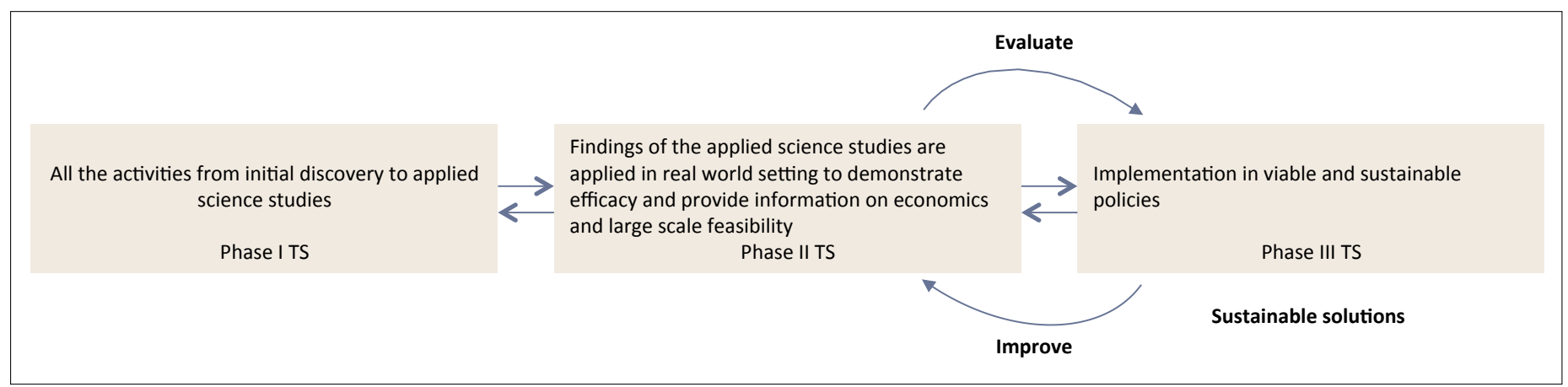

Fig. 2. The translational science (TS) model adapted to wider fields.

Among others, these two examples illustrate how long a path can be until an initial discovery is transformed into a real life application: 125 years were required to elaborate the first practical photovoltaic cell and, after 117 years, the potential average temperature increase due to green house gas remains in the same range and concrete measures still need to be defined.

What would have been the timeline and benefits of applying a translational science approach to this research? Although it is impossible to answer this question, we can still reasonably postulate that bringing specialists together fosters scientific and knowledge exchange, and should facilitate the translation of basic discoveries into practical applications - the creation of universities, competence centres, journals, and conferences can attest this. Furthermore, the Manhattan Project (1942-1945) led to the creation of the first nuclear reactor over a very short period of time considering the complexity and danger of the research. ${ }^{[11]}$ Despite the negative consequences of the Project and of the issues related to radioactivity, the access to nuclear power production has dramatically changed our society.

However, the translational science approach should not be considered as a panacea and many challenges are associated with its application to other fields. In the context of global change, how should the humanities be integrated when a translational science approach is applied?

What is the added value of this kind of approach? Humanities may help to understand motivation and behaviour around people's choice. For instance, the Swiss population embraced the decision made by Federal Council on 25 May 2011 to eliminate the production of nuclear power by $2050 .{ }^{[12]}$ However, the population is reluctant to change their consumption habits and many wind farm projects have been blocked. ${ }^{[13,14]}$ This is rather surprising considering that windmills and wind pumps, which also have a visual and noise impact, were traditionally used; windmills have become iconic structures of the Netherlands. However, the size of the installation and the noise frequency should be considered. What would have been the developments if a translational science policy/programme, including information on the perils of climate change, had been initiated following the announcement made on 25 May 2011 that Switzerland would replace nuclear power by other energy sources?

Humanities may facilitate dialogue with civil society and establish a better mutual understanding, which might be a prerequisite for a successful policy to address global change. Why should non-scientists follow experts' recommendations without receiving explanations or answers to their questions? Non-scientists are unfamiliar with most scientific theories and have beliefs and opinions which were acquired during their lives - e.g. what proportion of the population is aware of the natural greenhouse gas effect? Specialists have learned scientific concepts and are aware of the latest developments in their fields which should be better communicated in order to escape the cliché that scientists belong in an ivory tower. The summary for policy makers in the latest IPCC report illustrates how complex scientific findings can be made more accessible. ${ }^{[10]}$ Humanities, such as cognitive and education sciences, may help to bridge the gap between these two groups. ${ }^{[15,16]}$ In their article, Sturgis and Allum provided a good overview of the controversies related to the lack of public understanding and knowledge. This phenomenon, also known as the deficit model, is the key explanation to science scepticism before analysing the importance of the knowledgeattitude interface. ${ }^{[16]}$ Their study revealed that the combination of good political knowledge, good understanding of the context together with scientific knowledge contribute to a favourable attitude towards science. Recently, Burgess reported that the implication across several studies of policy makers or practice leaders in deliberative teams lead to the creation of practical knowledge and measures.[15] These examples illustrate the importance of the human component in science policy.

What are the limitations of the translational science approach? All parties involved must be willing to work together towards a common goal rather than pursuing individual goals. This means that each partner should acknowledge that each step involved in the process is important and that success is bound to collaboration. Therefore, strong ethics are required to make sure that the best result is delivered to the market rather than having a succession of small products which confer a moderate improvement compared to the previous one. Finally, the cultural aspects should be taken into account given that a successful approach in a given setting might be inefficient in another locality.

In conclusion, it is worth considering the feasibility of extending the translational science approach to other fields (Fig. 2). However, it should be kept in mind that, as for methods, techniques, and tools, this approach might be more suitable for some topics rather than others. The only way to verify this hypothesis is to apply the scientific method by experimenting the approach and successfully replicating the results. This remains a challenge in the immediate future.

Received: July 14, 2014

[1] S. H. Curry, 'Translational science: past, present, and future', Biotechniques 2008, $44,2$.

[2] M. Lean, J. Mann, J. Hoek, R. Elliot, G. Schofield, 'Translational research', BMJ 2008, 337.

[3] S. H. Woolf, 'The meaning of translational research and why it matters', Jama 2008, 299, 211.

[4] E. R. Dougherty, 'Translational science: epistemology and the investigative process', Current genomics 2009, 10, 102.

[5] P. Technicienne, C. Ochin, 'Recherche translationnelle: effet de mode ou réalité?', Le Courrier de la Transplantation 2009, IX, 3

[6] A. E. Becquerel, 'Recherches sur les effets de la radiation chimique de la lumière solaire au moyen des courants électriques', Comptes Rendus de L'Académie des Sciences 1839, 9, 145.

[7] A. E. Becquerel, 'Recherches sur les effets de la radiation chimique de la lumière solaire au moyen des courants électriques', Annalen der Physik und Chemie 1841, 54, 18 . 
[8] American Physical Society, 'This Month in Physics History - April 25, 1954: Bell Labs Demonstrates the First Practical Silicon Solar Cell', APS News 2009, 18, 2.

[9] S. Arrhenius, 'On the influence of carbonic acid in the air upon the temperature on the ground', Philosophical Magazine and Journal of Science 1896, 41, 237.

[10] IPCC 'Summary for Policymakers', in 'Climate Change 2013: The Physical Science Basis, Contribution of Working Group I to the Fifth Assessment Report of the Intergovernmental Panel on Climate Change', 2013, pp 16 Cambridge University Press, Cambridge, United Kingdom and New York, NY, USA.

[11] 'Manhattan Project', Encyclopedia Britannica, retrieved 27 June 2014, from http://www.britannica.com/EBchecked/topic/362098/Manhattan-Project.

[12] Swiss Federal Office of Energy, 'Federal Council decides to gradually phase out nuclear energy as part of its new energy strategy', Retrieved 27 June 2014, from http://www.admin.ch/aktuell/00089/index.html?lang=en\&msg$\mathrm{id}=39337$.

[13] ATS, 'Daillens et Oulens refusent le projet de parc éolien', La Côte, retrieved 27 June 2014, from http://www.lacote.ch/fr/regions/vaud/daillenset-oulens-refusent-le-projet-de-parc-eolien-2138-1192891

[14] S. Jaberg, 'Un vent de fronde souffle sur les éoliennes du Jura', swissinfo. ch, retrieved 27 June 2014, from http://www.swissinfo.ch/fre/societe/Un vent_de_fronde_souffle_sur_les_eoliennes_du_Jura.html?cid=31479634.

[15] M. M. Burgess, 'From 'trust us' to participatory governance: Deliberative publics and science policy', Public understanding of science 2014, 23, 48.

[16] P. Sturgis, N. Allum, 'Science in society: re-evaluating the deficit model of public attitudes', Public understanding of science 2004, 13, 55. 